\title{
Environmental Monitoring of Heavy Metals and Arsenic in Soils Adjacent to CCA-Treated Wood Structures in Gangwon Province, South Korea
}

\author{
Ahmed A. Abdelhafez, Yasser M. Awad, Min Su Kim ${ }^{1)}$, Kwang Joon Ham ${ }^{1)}$, \\ Kyoung Jae Lim, Jin Ho Joo, Jae E Yang, and Yong Sik Ok \\ College of Agriculture and Life Sciences, Kangwon National University, Chuncheon 200-701, Korea \\ ${ }^{1)}$ Natural Environment Research Office, Hongcheon, Korea \\ (Received November 12, 2009, Accepted December 25, 2009)
}

\begin{abstract}
Chromated copper arsenate (CCA) is a chemical wood preservative that has been intensively used to protect wood from decay during the last few decades. CCA is widely used to build structures such as decks, fences, playgrounds and boardwalks. However, structures constructed of CCA-treated wood have caused adverse environmental effects due to leaching of $\mathrm{Cr}, \mathrm{Cu}$ and $\mathrm{As}$ into surrounding soils. This research was conducted to monitor the vertical and horizontal distribution of $\mathrm{Cr}, \mathrm{Cu}$ and $\mathrm{As}$ in soils adjacent to CCA-treated wood structures in Korea. Two structures constructed with CCA-treated wood were selected at Hongcheon and Chuncheon in Gangwon Province, South Korea. Eleven soil profile samples were collected at depths of 0 to $80 \mathrm{~cm}$ at each site, while 12 surface soil samples were collected at distances of 0 to 200 $\mathrm{cm}$ from each structure. The soil chemical properties, soil particle size distribution and total metal concentrations were then determined. The results revealed that soils near CCA-treated wood structures were generally contaminated with $\mathrm{Cr}, \mathrm{Cu}$ and $\mathrm{As}$ when compared to the background concentration of each metal. In addition, the concentrations of $\mathrm{Cr}, \mathrm{Cu}$ and $\mathrm{As}$ in soils decreased as the vertical and horizontal distance from the structure increased. Further studies should be conducted to evaluate the mobility and distribution of these metals in the environment as well as to develop novel technologies for remediation of CCA contaminated soils.
\end{abstract}

Key Words: Chromated copper arsenate, Wood preservative, Soil, pH, Heavy metals, Leaching

\section{INTRODUCTION}

Chromated copper arsenate (CCA) is a representative wood preservative that is used to prevent decay of wood by bacteria, fungi and termites ${ }^{1)}$. During the last several decades, CCA has been used to treat wood structures such as utility poles and children's playgrounds in many countries ${ }^{2}$. Indeed, it has been reported that CCA-treated wood accounts for more than $80 \%$ of the total treated wood in the United States ${ }^{3)}$.

*연락저자:

Tel: +82-33-250-6443 Fax: +82-33-241-6640

E-mail: soilok@kangwon.ac.kr
In Korea, CCA-treated wood has been used extensively since the 1980s to build decks, picnic tables, fences, walkways, playground structures and sound barriers ${ }^{4}$. The Korea Forest Research Institute (KFRI) has estimated that CCA-treated wood represents over $90 \%$ of the treated wood market (by volume) in Korea ${ }^{2)}$. Of the three types of CCA (A, B and C), type $\mathrm{C}$ is the most commonly used in Korea. This type of CCA is composed of $47.5 \%$ $\mathrm{CrO}_{3}, 18.5 \% \mathrm{CuO}$ and $35 \% \mathrm{As}_{2} \mathrm{O}_{5}{ }^{5}$.

Several studies have shown that $\mathrm{Cr}, \mathrm{Cu}$ and As leach from structures built using CCA-treated wood, resulting in contamination of the surrounding soils ${ }^{6,7)}$. Additionally, it has been reported that As is the most mobile element of the components of CCA. However, the concentration 
gradients of $\mathrm{Cr}, \mathrm{Cu}$ and As around CCA treated structures appear to be limited to $100-150 \mathrm{~cm}$ in both the horizontal and vertical distribution ${ }^{8,9)}$.

Public concern regarding soil contamination and human health problems associated with the leaching of $\mathrm{Cr}, \mathrm{Cu}$ and As from CCA-treated wood has increased in recent years ${ }^{10,11)}$. Accordingly, the European Commission (EU) issued a directive restricting the use of wood preservatives that contain As in August of 2004 ${ }^{12)}$. The USEPA also banned the use of CCA-treated wood for residential purposes such as children's playgrounds, decks, picnic tables, landscaping timbers, residential fencing and walkways in January of $2004^{13)}$. Additionally, the Korean government prohibited the use of CCA-treated wood on August 1, 2007. As a result, CCA-treated wood has been removed from the market in Korea ${ }^{14)}$; however, residential structures containing CCA-treated wood are still widespread throughout the country. Therefore, long-term monitoring of CCA-treated wood structures is necessary to evaluate their effects on the surrounding environment. This study was conducted to assess the horizontal and vertical distribution of $\mathrm{Cr}, \mathrm{Cu}$ and As in soils surrounding CCA-treated wood structures in Gangwon Province, Korea.

\section{MATERIALS AND METHODS}

\section{On-site identification of CCA treated wood structures}

On-site identification of CCA-treated wood structures was conducted using two types of indicators, Chrome Azurol and PAN stains ${ }^{15)}$. Chrome Azurol stain was prepared by adding $0.6 \mathrm{~g}$ of Chrome Azurol S and $5 \mathrm{~g}$ of sodium acetate to $500 \mathrm{~mL}$ of ethanol. PAN was prepared at $0.065 \%$ by weight by dissolving the compound in methanol to create a reagent that could be sprayed over wood. To determine if the samples contained CCA, the surface of the test material was sanded, after which each stain was sprayed onto the surface. As shown in Fig. 1, development of a deep blue color following application of the Chrome Azurol stain or a red color following application of the PAN stain within one minute indicated the presence of copper.

\section{Sampling}

Two locations were selected to evaluate CCA-treated wood structures (Fig. 2). Specifically, a site that has been in use for five years in Chuncheon, which is the capital of Gangwon Province, and a site that has been

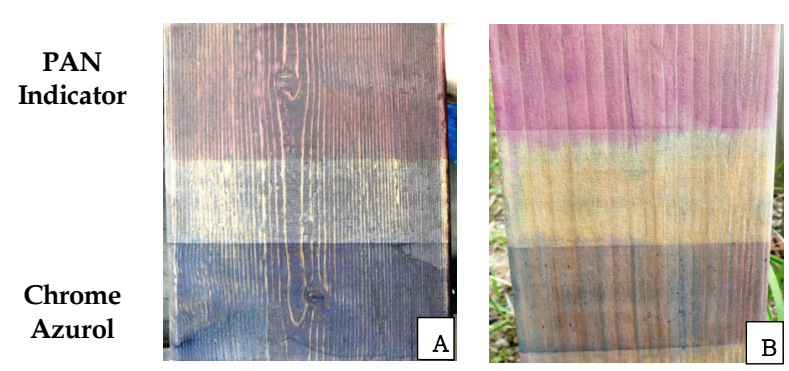

Fig. 1. Stained samples of CCA-treated wood structures at Hongcheon (A) and Chuncheon (B) in Gangwon Province, Korea. The formation of a pink and blue color in response to application of PAN indicator and Chrome Azurol, respectively, indicate that the wood was treated with CCA.
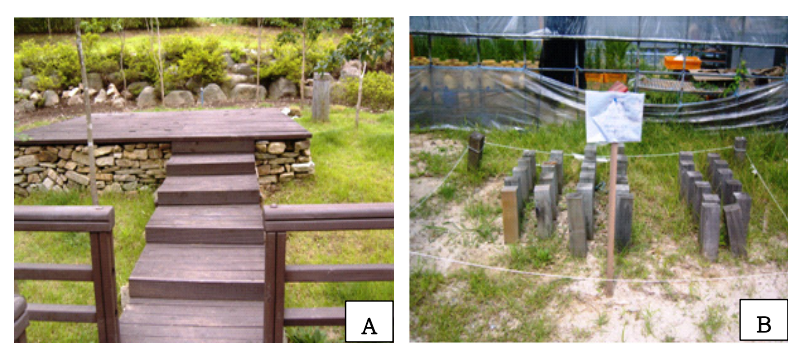

Fig. 2. View of CCA-treated wood structures at Hongcheon (A) and Chuncheon (B) in Gangwon Province, Korea.

in use for six years in a national park in Hongcheon were evaluated. The metrological data indicates that the sites are characterized by heavy annual rainfall, with averages of 1291.3 and $1266.8 \mathrm{~mm}$ for Hongcheon and Chuncheon, respectively. Eleven soil samples were collected adjacent to each structure at depths of $0-1$, $1-5,5-10,10-15,15-20,20-25,25-30,30-35$, 35-40, 40-60 and $60-80 \mathrm{~cm}$ using a tube auger to determine the vertical distributions of $\mathrm{Cr}, \mathrm{Cu}$ and $\mathrm{As}$ at each location. In addition, 12 surface soil samples were collected from a 0-30 cm depth at distances of 0-2, 2-4, 4-6, 6-8, 8-10, $10-20,20-30,30-40,40-50,50-100,100-150$ and 150-200 $\mathrm{cm}$ from the structures constructed of CCA treated wood. Soil samples were air-dried and then passed through a 2-mm sieve after removing the coarse fragments, roots and debris, after which they were subjected to the analyses described below. In addition, wood samples were collected from the structures constructed of CCA treated wood at Chuncheon and Hongcheon. The wood samples were air-dried, ground and passed through a 2-mm sieve, after which they were subjected to further chemical analysis. 


\section{Analyses}

The particle size distribution was determined using the pipette method as described by Akoto, et al. ${ }^{16}$. The soil $\mathrm{pH}$ and electrical conductivity (EC) were measured in 1:5 deionized water/soil extracts at room temperature ${ }^{17}$. Soil and wood samples were digested using a microwave (Mars-X, HP-500 plus, CEM Corporation) according to the USEPA methods 3051 and 3052, respectively ${ }^{18,19}$. For microwave digestion, the power setting was held at 1600 watts to digest all 40 samples. Overall, $0.5 \mathrm{~g}$ of each soil sample was digested using $10 \mathrm{~mL}$ of concentrated nitric acid $(60 \%)$ in a microwave by ramping the temperature to $175^{\circ} \mathrm{C}$ over 5.5 minutes, where it was held for 4.5 minutes. Additionally, $0.2 \mathrm{~g}$ of each wood sample was digested using a mixture of $10 \mathrm{~mL} 60 \%$ nitric acid and $2 \mathrm{~mL} \mathrm{30 \%} \mathrm{hydrogen} \mathrm{peroxide,} \mathrm{after} \mathrm{which} \mathrm{it} \mathrm{was}$ heated to $180 \pm 5^{\circ} \mathrm{C}$ and held at that temperature for $9.5 \mathrm{~min}$. The extract was then centrifuged, after which the supernatant was diluted to $50 \mathrm{~mL}$ using deionized water. The total contents of $\mathrm{Cr}, \mathrm{Cu}$ and $\mathrm{As}$ in the soil and wood extracts were determined using inductively coupled plasma atomic emission spectroscopy (ICP-AES).

\section{RESULTS AND DISCUSSIONS}

Soil properties and $\mathrm{Cr}, \mathrm{Cu}$ and As contents of CCA treated wood

Table 1 shows the particle size distribution of surface soil samples collected from the sites at Hongcheon and Chuncheon. Soils at both locations were classified as sandy loam, but soil at Hongcheon contained a higher amount of clay $(10 \%)$ than soil at Chuncheon $(4.7 \%)$. The average $\mathrm{pH}$ of the soil profile samples at Chuncheon and Hongcheon ranged from 6.36 to 7.81 and 5.38 to 5.96 , respectively (Fig. 3). These findings indicate that the surface soil $\mathrm{pH}$ at Chuncheon was within the neutral range (with an average of 6.5), whereas that of Hongcheon was slightly acidic (with an average of 5.42). Table 2 shows the EC values of the soil samples collected from each location. The highest EC values, which were 0.056 and $0.033 \mathrm{dS} \mathrm{m}^{-1}$ for Chuncheon

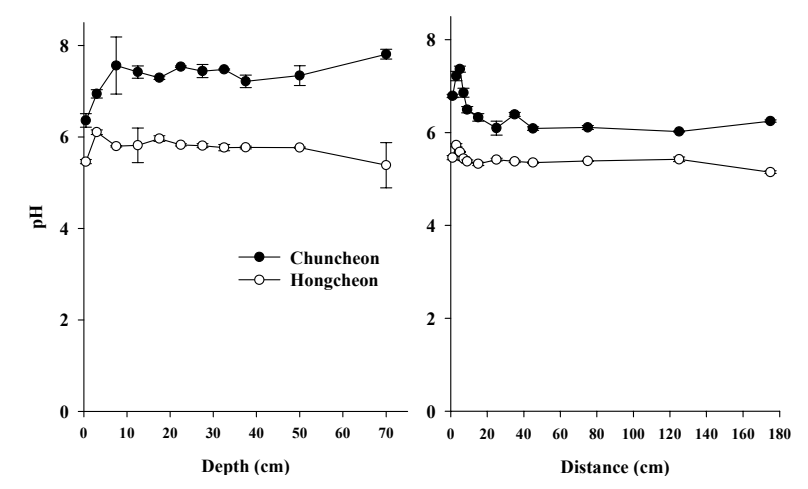

Fig. 3. $\mathrm{pH}$ of profile soil samples collected at depths of 0-1 to $60-80 \mathrm{~cm}$ and surface soils collected at distances of $0-2$ to $150-200 \mathrm{~cm}$ from the structures at the study locations.

Table 1. Particle size distribution of surface soils collected from Gangwon Province, Korea

\begin{tabular}{ccccc}
\hline \multirow{2}{*}{ Location } & \multicolumn{3}{c}{ Particle size distribution \% } & Texture \\
\cline { 2 - 5 } & Sand & Silt & Clay & Sandy loam \\
Chuncheon & 73.60 & 21.73 & 4.67 & Sandy loam \\
Hongcheon & 62.05 & 27.61 & 10.33 & San \\
\hline
\end{tabular}

Table 2. EC of surface soils collected from Gangwon Province, Korea

\begin{tabular}{cccc}
\hline Depth/Distance & Direction & \multicolumn{2}{c}{ EC dS m $^{-1}$} \\
\cline { 3 - 3 }$(\mathrm{cm})$ & & Chuncheon & Hongcheon \\
\hline $0-1$ & Vertical & $0.050 \pm 0.013$ & $0.033 \pm 0.00$ \\
$1-5$ & & $0.044 \pm 0.006$ & $0.043 \pm 0.004$ \\
$40-60$ & & $0.027 \pm 0.007$ & $0.031 \pm 0.00$ \\
$60-80$ & & $0.063 \pm 0.028$ & $0.025 \pm 0.00$ \\
\hline $0-2$ & & $0.056 \pm 0.001$ & $0.033 \pm 0.00$ \\
$2-4$ & Horizontal & $0.043 \pm 0.001$ & $0.027 \pm 0.00$ \\
$100-150$ (Background) & & $0.030 \pm 0.00$ & $0.033 \pm 0.00$ \\
$150-200$ (Background) & & $0.017 \pm 0.002$ & $0.046 \pm 0.00$ \\
\hline
\end{tabular}


Table 3. $\mathrm{Cr}, \mathrm{Cu}$ and As contents in CCA treated wood from Gangwon Province, Korea

\begin{tabular}{cccc}
\hline \multirow{2}{*}{ CCA-treated wood site } & \multicolumn{3}{c}{ Concentration $\left(\mathrm{mg} \mathrm{kg}^{-1}\right)$} \\
\cline { 2 - 4 } & $\mathrm{Cr}$ & $\mathrm{Cu}$ & As \\
\hline Hongcheon & $3320.74 \pm 19.93$ & $1342.94 \pm 2.09$ & $825.05 \pm 6.184$ \\
Chuncheon & $2636.34 \pm 15.59$ & $1305.97 \pm 35.42$ & $1198.67 \pm 234.20$ \\
\hline
\end{tabular}

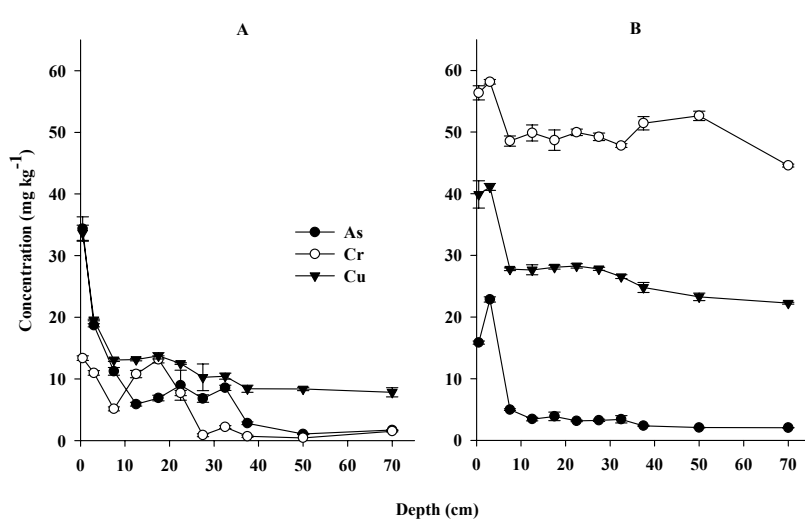

Fig. 4. Vertical distribution of $\mathrm{Cr}, \mathrm{Cu}$ and $\mathrm{As}\left(\mathrm{mg} \mathrm{kg}^{-1}\right)$ in profile soil samples collected from (A) Chuncheon and (B) Hongcheon in Gangwon Province, Korea.

and Hongcheon, respectively, were observed in surface soil samples. Generally, the EC values decreased as the distance from the structures constructed using CCAtreated wood increased.

Table 3 shows the total $\mathrm{Cr}, \mathrm{Cu}$ and As content of CCA treated wood collected from the structures at Hongcheon and Chuncheon. The results showed that the mean concentrations of $\mathrm{Cr}, \mathrm{Cu}$ and As in the CCAreated wood at Hongcheon were 3320.74, 1342.94 and $825.05 \mathrm{mg} \mathrm{kg}^{-1}$, respectively, while they were 2636.34, 1305.97 and $1198.67 \mathrm{mg} \mathrm{kg}^{-1}$, respectively, at Chuncheon. Similar findings were observed by Aceto et al. ${ }^{20)}$ and Dawson et al. ${ }^{21}$, who found that the concentrations of $\mathrm{Cr}, \mathrm{Cu}$ and $\mathrm{As}$ in wood samples ranged from 1000 to $5000 \mathrm{mg} \mathrm{kg}^{-1}$. Overall, the highest concentrations of As were observed in CCA-treated wood collected from Chuncheon, while the highest concentrations of $\mathrm{Cr}$ and $\mathrm{Cu}$ were detected in CCA-treated wood collected from Hongcheon.

Vertical and horizontal distributions of $\mathrm{Cr}$, $\mathrm{Cu}$ and $\mathrm{As}$ in soil

Figure 4 shows the distribution of leached CCA elements in soil samples collected at Chuncheon and Hongcheon. At Chuncheon, the highest total concentrations of $\mathrm{Cr}, \mathrm{Cu}$ and $\mathrm{As}$ in soil at a depth of $0-1 \mathrm{~cm}$ were

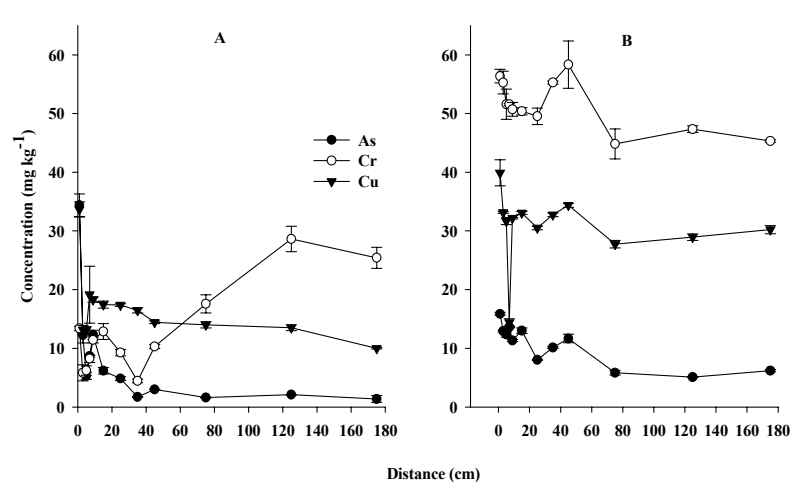

Fig. 5. Horizontal distribution of $\mathrm{Cr}, \mathrm{Cu}$ and As concentrations $\left(\mathrm{mg} \mathrm{kg}^{-1}\right)$ in surface soil samples collected from (A) Chuncheon and (B) Hongcheon in Gangwon Province, Korea.

13.38, 33.65 and $34.38 \mathrm{mg} \mathrm{kg}^{-1}$, respectively. The highest concentrations of $\mathrm{Cr}, \mathrm{Cu}$ and $\mathrm{As}$ at Hongcheon were found to be $58.15,41.11$ and $22.86 \mathrm{mg} \mathrm{kg}^{-1}$, respectively, and these values were observed at soil depths of 1-5 $\mathrm{cm}$. These findings are similar to the results of a previous study conducted at the same location by Kim et al. ${ }^{22}$, who found that the average concentrations of $\mathrm{Cr}, \mathrm{Cu}$, and As in surface soil samples collected from underneath the structures constructed from CCA-treated wood were 50.10, 28.7 and $7.52 \mathrm{mg} \mathrm{kg}^{-1}$, respectively, indicating that $\mathrm{As}$ and $\mathrm{Cu}$ can easily be leached over time from structures constructed of CCA-treated wood. Overall, the concentrations of the metals in the soil at Chuncheon and Hongcheon were $\mathrm{Cu}>\mathrm{As}>\mathrm{Cr}$ and $\mathrm{Cr}>\mathrm{Cu}>\mathrm{As}$, respectively.

Figure 5 shows the horizontal distribution of metals in surface soil samples collected from each location at depths of $0-30 \mathrm{~cm}$. The concentrations of leached CCA elements clearly decreased as the distance from the structure constructed of CCA-treated wood increased, except for $\mathrm{Cr}$ at the Chuncheon location. The highest concentration of As (34.38 mg kg-1) was found at $0-2$ $\mathrm{cm}$ from the structure constructed of CCA-treated wood, while the As concentration of the background soil was $1.37 \mathrm{mg} \mathrm{kg}^{-1}$ at the Chuncheon location. The highest concentration of $\mathrm{Cu}$ was found at a distance of 0-2 
$\mathrm{cm}$ from the CCA-treated structure, after which it decreased as the distance increased. The highest concentrations of $\mathrm{Cr}, \mathrm{Cu}$ and $\mathrm{As}$ (56.37, 39.89 and $15.87 \mathrm{mg} \mathrm{kg}^{-1}$, respectively) were found in surface soil samples collected at $0-2 \mathrm{~cm}$ from the CCA-treated structures at Hongcheon. These values were higher than the background values of 45.32, 30.22 and $6.19 \mathrm{mg} \mathrm{kg}^{-1}$ for $\mathrm{Cr}, \mathrm{Cu}$ and As, respectively.

The concentrations of $\mathrm{Cr}, \mathrm{Cu}$ and As in soil near the structures constructed of CCA-treated wood were varied with both soil depth and the distance from the wood structure at both studied locations. The concentrations were generally found to follow the order of $\mathrm{Cu}>\mathrm{As}$ $>\mathrm{Cr}$ and $\mathrm{Cu}>\mathrm{Cr}>$ As for the profile and surface soil samples collected at Chuncheon, respectively, while they were in the order of $\mathrm{Cr}>\mathrm{Cu}>$ As for both the profile and surface soil samples collected at Hongcheon. The concentrations of $\mathrm{Cr}, \mathrm{Cu}$ and As typically decreased as the depth of soil and the distance from the CCA-treated structure increased, which is in agreement with the results of previous studies ${ }^{4,22,23,24)}$. There were also high increases in the concentrations of metals in soils collected from the two studied locations when compared with the concentrations of background soils. Taken together, these findings indicate that $\mathrm{Cr}, \mathrm{Cu}$ and As can easily leach and become mobile in surrounding soils, which is similar to the results of studies conducted by Stilwell and Graetz ${ }^{25)}$ and Jang et al. $^{26)}$.

Several factors may have contributed to the differences in concentrations of $\mathrm{Cr}, \mathrm{Cu}$ and As among soil samples collected at Chuncheon and Hongcheon. Specifically, the concentrations of $\mathrm{Cr}$ and $\mathrm{Cu}$ in the CCA-treated wood collected from Hongcheon were higher than those of the wood that was collected from Chuncheon, which corresponded to the concentrations observed in the soils surrounding the structures at both sites. In addition, the period of service use may have played a role in the concentrations of $\mathrm{Cr}, \mathrm{Cu}$ and As in the soil surrounding the CCA-treated structures. Furthermore, higher concentrations were observed in the soil surrounding the structure at Hongcheon, which had a longer service time (6 years) than the structure at Chuncheon (5 years). Moreover, the lower soil $\mathrm{pH}$ may have led to increased leaching of the metals from the constructed CCA-wood into the surrounding soils in conjunction with intensive rainfall ${ }^{10,11,27)}$. The average $\mathrm{pH}$ of the surface soil and soil profile samples at Hongcheon (5.77 and 5.42, respectively) led to increased leaching of the metals from the constructed
CCA-wood when compared to the $\mathrm{pH}$ of surface and profile soil samples collected from Chuncheon (7.31 and 6.5 , respectively). Finally, the clay fraction percentage $(10 \%)$ was higher at Hongcheon than $(4.7 \%)$ at Chuncheon, which may have resulted in decreased leaching at Hongcheon due to the metals sorbing to the clay particles ${ }^{26}$. Overall, the following factors likely impacted the leaching of elements from the CCA-treated wood structures: 1) the direct contact of CCA-treated wood with the soil, 2) the period of service use, and 3) the retention level of the treated wood.

\section{CONCLUSIONS}

This study demonstrated that $\mathrm{Cr}, \mathrm{Cu}$ and $\mathrm{As}$ are released from CCA-treated wood, after which they migrate vertically and horizontally into the surrounding soils. The distribution of $\mathrm{Cr}, \mathrm{Cu}$ and As in surface and profile soils collected from adjacent to structures constructed from CCA-treated wood at Hongcheon and Chuncheon varied in response to the period of service use, the soil particle size distribution and the soil $\mathrm{pH}$. In addition, the $\mathrm{Cr}$ concentration gradient was the highest, followed by $\mathrm{Cu}$ for the horizontal distribution at both locations. The USEPA has listed $\mathrm{Cr}, \mathrm{Cu}$ and As as high risk pollutants based on the results of several studies of the impacts of long-term use of CCA-treated wood during the last few decades. Additionally, the use of CCA-treated wood in the construction of parks, fences, ground planks and houses is considered to be a major source for the release of $\mathrm{Cr}, \mathrm{Cu}$ and $\mathrm{As}$ into the environment. In the present study, high levels of $\mathrm{Cr}, \mathrm{Cu}$ and As were found in the soils surrounding two structures constructed of CCA-treated wood. These findings indicate that long-term monitoring is required to assess the impacts of CCA-treated wood structures on the environment. Furthermore, development of novel technologies is required for the remediation of CCA contaminated soils.

\section{ACKNOWLEDGEMENTS}

This work was supported by National Research Foundation of Korea Grant funded by the Korean Government (Project number: 2009-0071439, Project title: Phytoremediation of Soils Contaminated with Wood Preservatives). 


\section{REFERENCES}

1. Ko, C. H., Chen, P. J., Chen, S. H., Chang, F. C., Lin, F. C., and Chen, K. K. (2009) Extraction of chromium, copper, and arsenic from CCA-treated wood using biodegradable chelating agents, Bioresour. Technol. (DOI:10.1016/j.biortech.2009.07.027). In press.

2. Jang, Y., Yoon, H., and Kang, H. (2006) Leaching behavior and flux of toxic metals from chromate cooper arsenate- treated wood and chromate copper arsenate-treated wood ash, Bull. Environ. Contam. Toxicol. 76, 471-480.

3. Rouhi, A. M. (2001) Wrestling with the plagues of wood, Chem. Eng. News 79, 56-57.

4. Kim, H., Song, B., and Koo, J. H. (2008) Spatial distribution of chromium, copper, and arsenic concentrations in soils near three log structures and a sound barrier, all constructed with CCA-treated wood, J. of KoSSGE. 13, 12-20.

5. Lebow, D. and Foster, J. E. (2004) Long-term soil accumulation of chromium, copper, and arsenic adjacent to preservative-treated wood, Bull. Environ. Contam. Toxicol. 72, 225-232.

6. Gezer, E. D., Yildiz, U. C., Temiz, A., Yildiz, S., and Dizman, E. (2005) $\mathrm{Cu}, \mathrm{Cr}$, and As distribution in soil adjacent to CCA-treated utility poles in Eastern Blacksea region of Turkey, Build. Environ. 40, 1684-1688.

7. Robinson, B., Greven, M., Green, S., Sivakumaran, S., Davidson, P., and Clothier, B. (2006) Leaching of copper, chromium, and arsenic from treated vineyard posts in Marlborough, New Zealand, Sci. Total Environ. 364, 113-23.

8. Zagury, G. J., Samson, R., and Deschenes, L. (2003) Occurrence of metals in soil and groundwater near chromated copper arsenate-treated utility poles, $J$. Environ. Qual. 32, 505-514.

9. Lebow, S. and Foster, D. (2005) Environmental concentrations of copper, chromium, and arsenic released from a chromated-copper-arsenate-(CCA-C-)treated wetland boardwalk, Forest Prod. J. 55, 62-70.

10. Cooper, P. A. (1991) Leaching of CCA from treated wood: pH effects, Forest Prod. J. 41, 30-30.

11. Kartal, S. N., Hwang, W. J., and Imamura, Y. (2007) Evaluation of effect of leaching medium on the release of copper, chromium, and arsenic from treated wood, Build. Environ. 42, 1188-1193.
12. European Commission, (2003) Commission Directive 2003/2/EC of 6 January 2003 relating to restrictions on the marketing and use of arsenic (tenth adaptation to technical progress to Council Directive 76/769/EEC), Official J. of the Eur. Commun. Brussels.

13. Rahman, F. A., Allan, D. L., Rosen, C. J., and Sadowsky, M. J. (2004) Arsenic availability from chromate copper arsenate (CCA)-treated wood, J. Environ. Qual. 32, 173-180.

14. Kim, H., Kim, D., Park, J., Shin, Y. S., Hwang, I. Y., and Kim, Y. K. (2006) Distribution of chromium, copper, and arsenic in soils adjacent to steps, a deck, and a sound barrier constructed with a wood preservative CCA-treated timbers, J. Kor. Soc. Soil Groundwat, Environ. 11, 54-65.

15. Blassino, M, Solo-Gabriele, H, and Townsend, T. (2002) Pilot scale evaluation of sorting technologies for CCA treated wood waste, Waste Manag. Res. 20, 290-301.

16. Akoto, O., Ephraim, J. H., and Darko, G. (2008) Heavy metals pollution in surface soils in the vicinity of abundant railway servicing workshop in Kumasi, Ghana, Int. J. Environ. Res. 2, 359-364.

17. NIAST (2000) Method of soil and plant analysis. National Institute of Agricultural Science and Technology (NIAST), Suwon, Korea. (In Korean).

18. Chirenje, T., Ma, L. Q., Chen, M., and Zillioux, E. J. (2003) Comparison between background concentrations of arsenic in urban and non-urban areas of Florida, Adv. Environ. Res. 8, 137-146.

19. Baba, K., Arao, T., Maejima, Y., Watanabe, E., Eun, H., and Ishizaka, M. (2008) Arsenic speciation in rice and soil containing related compounds of chemical warfare agents, Anal. Chem. 80, 5768-5775.

20. Aceto, M. and Fedele, A. (1994) Rain water effect on the release of arsenic, copper and chromium from treated wood, Fresenius Environ. Bull. 3, 389-394.

21. Dawson, B. S. W., Parker, G. F., Cowan, F. J., and Hong, S. O. (1991) Inter-laboratory determination of copper chromium and arsenic in timber treated with wood preservative, Analyst 116, 339-346.

22. Kim, H., Kim, D. J., Koo, J. H., Park, J. G., and Jang, Y. C. (2007) Distribution and mobility of chromium, copper, and arsenic in soils collected near CCAtreated wood structure in Korea, Sci. Total Envion. 374, 273-281.

23. Chirenje, T., Ma, L. Q., Clark, C., and Reeves, M. (2003) $\mathrm{Cu}, \mathrm{Cr}$ and As distribution in soil adjacent 
to pressure-treated decks, fences and poles, Environ. Pollut. 124, 407-417.

24. Morrell, J. J. and Huffman, J. (2004) Copper, chromium and arsenic levels in soils surrounding posts treated with chromated copper arsenate (CCA), Wood and Fiber Sci. 36, 119-28.

25. Stilwell, D. E. and Graetz, T. J. (2001) Copper, chromium, and arsenic levels in soil near highway traffic sound barrier built using CCA pressure-treated wood, Bull. Environ. Contam. Toxicol. 67, 303-308.
26. Jang Y. C., Townsend, T. G., Ward, M., and Bitton, G. (2002) Leaching of arsenic, chromium, and copper in a contaminated soil at a wood preserving site, Bull. Environ. Contam. Toxicol. 69, 808-16.

27. Khan, B. I., Solo-Gabriele, H. M., Townsend, T. G., and Yong, C. A. I. (2006) Release of arsenic to the environment from CCA-treated wood. 1. Leaching and speciation during service, Environ. Sci. Technol. 40, 988-993. 